Escuela de Ciencias Sociales y Humanidades, UNED, C.R.

URL: http://investiga.uned.ac.cr/revistas/index.php/espiga/index

ISSN: 1409-4002 • e-ISSN: 2215-454X

doi: http://dx.doi.org/10.22458/re.v16i0.1930

\title{
Ruta de producción Casa en tierra ajena. Documental sobre migración forzada en Centroamérica
}

\author{
Ivannia Villalobos-Vindas*
}

\author{
Recibido: 29 de mayo, 2017 • Aceptado: 18 de octubre, 2017
}

\section{RESUMEN}

La Universidad Estatal a Distancia (UNED), a sus 40 años de ser fundada, acumula una experiencia de producción de material didáctico del género documental de gran calidad, tanto a nivel del país como de la región. Esto ha sido reconocido en los más de 40 premios o reconocimientos nacionales e internacionales hacia la producción realizada concretamente desde el Programa de Producción de Material Audiovisual (PPMA).

Cada proceso de producción audiovisual tiene sus ritmos y particularidades. En el siguiente artículo se exponen las etapas y decisiones clave en la ruta de producción del documental sobre migración forzada en Centroamérica Casa en tierra ajena, una producción de la Universidad Estatal a Distancia (UNED) y la Universidad de Costa Rica (UCR), con el apoyo financiero del Consejo Nacional de Rectores (CONARE). En el año del 40 aniversario de la UNED, se estrenó Casa en tierra ajena, el primer largometraje documental realizado por la UNED con una escala de producción y grabación que abarca Centroamérica y México, el cual continúa con el compromiso e impacto característico de las producciones UNED, la difusión y el impacto global. Como herramienta de aprendizaje, este artículo aborda los aspectos relacionados con los factores que influyeron en la construcción del proyecto y los objetivos del equipo de producción en un documental educativo y de incidencia social. Además, se describen los momentos o decisiones clave en las etapas de preproducción, producción y posproducción que condujeron a un proceso de producción riguroso en lo académico y sensible en la dimensión humana.

Palabras claves: Migración, producción documental, Centroamérica, hospitalidad.

\section{Formato de citación según APA}

Villalobos-Vindas, I. (2017). Ruta de producción Casa en tierra ajena. Documental sobre migración forzada en Centroamérica. Revista Espiga, 16(Número Especial), 88-103. doi: http://dx.doi.org/10.22458/re.v16i0.1930

Formato de citación según Chicago

Villalobos-Vindas, Ivannia «Ruta de producción Casa en tierra ajena. Documental sobre migración forzada en Centroamérica». Revista Espiga 16, n. ${ }^{\circ}$ Especial (2017): 88-103. doi: http://dx.doi.org/10.22458/re.v16i0.1930

* M. EL. Ivannia Villalobos Vindas, Productora Audiovisual, Universidad Estatal a Distancia, Costa Rica. Correo electrónico: ivillalobos@uned.ac.cr 


\section{Introducción}

La ley de creación de la Universidad Estatal a Distancia (UNED) en 1977, destacó la importancia de un modelo de educación a distancia apoyado en los medios de comunicación social. De esta manera, a lo largo de sus 40 años de trayectoria, la universidad reúne experiencia en mediación pedagógica de contenidos audiovisuales, innovación tecnológica, diversidad narrativa y diversificación de los canales de difusión para su población estudiantil y la comunidad nacional e internacional.

La producción realizada desde el Programa de Producción de Material Audiovisual (PPMA) es sumamente diversa, tanto en el área de video como radiofónica. En lo que respecta al video se producen series televisivas empleadas en diversas Cátedras, como es el caso de las producciones sobre contenidos literarios La Noche en el Paraíso, Punto y Coma; producciones didácticas en distintas áreas del conocimiento como Anacy, Estadística, Arthropoda, Fauna de Costa Rica; series didácticas animadas como Somos el principio del cambio sobre el tema de cambio climático; documentales históricos como Viaje al 56 sobre la gesta heroica de 1956; y proyectos en convenio con otras instituciones del Estado como Minuto Final, que aborda los minutos del expresidente Juanito Mora, trabajado con el Ministerio de Educación Pública.

En el ámbito radiofónico también se registra una producción numerosa y diversa, entre ellas Historias Paralelas, cuyos programas son empleados en cursos de la Cátedra de Historia; El Grito de la Tierra, que documenta las luchas socioambientales en Costa Rica; Vivir con Valor un programa de servicio a la comunidad nacional y el rescate de valores; así como una copiosa producción de adaptaciones radiofónicas de cuentos infantiles.

En la última década se han dado transformaciones significativas que van desde el uso intensivo del lenguaje de la animación en 2D y 3D, publicación libre en Internet de la producción audiovisual de la UNED en el repositorio audiovisuales.uned.ac.cr, implementación de subtitulaje de producciones en diversos idiomas y producción de documentales transmediáticos e interactivos, entre otros. A nivel tecnológico también se dio la transición de la producción en definición estándar ( $\mathrm{SD}$, por sus siglas en inglés) a la alta definición (HD, por siglas en inglés).

La trayectoria y experiencia de la Universidad Estatal a Distancia (UNED) concretamente desde el Programa de Producción de Material Audiovisual (PPMA) da cuenta de una diversidad de temáticas, estructuras narrativas y mediación pedagógica para concretar materiales audiovisuales, del género documental, de alta calidad técnica y de contenido con impacto en la docencia, la investigación y la extensión.

Estas características se encuentran reunidas en el documental Casa en tierra ajena, el cual ha sido declarado de interés interinstitucional por el Consejo Nacional de Rectores (CONARE), según Acuerdo CNR-094-17, como parte de la Declaratoria de Universidades Públicas por la Vida, el Diálogo y la Paz, del 2017.

La realización del documental sobre migración forzada en Centroamérica, Casa en tierra ajena, responde a una necesidad de llevar la investigación científica social al lenguaje audiovisual, procurando que el tema sea visibilizado y analizado desde distintos sectores sociales, sobre todo en el contexto actual donde se radicalizan los discursos y las 
políticas antiinmigrantes en una región como Centroamérica; en la cual, entre un $12 \%$ y $14 \%$ de su población ha migrado, principalmente a los Estados Unidos.

Lo anterior reta a pensar Centroamérica desde otras perspectivas que parten del conocimiento de sus diversas realidades y no solamente desde los estereotipos o nociones superficiales. Casa en tierra ajena procura brindar una visión histórica y contemporánea profunda sobre los factores de expulsión, los mecanismos de control y la solidaridad en un lenguaje accesible a estudiantes, académicos, comunidades, etc. Es un documental que puede ser analizado desde distintas disciplinas: las relaciones internacionales, la historia, teorías del desarrollo, trabajo social, derechos humanos, etc.

De esta manera, se pretende posicionar el derecho a migrar, pero también el derecho a no migrar, cuya movilidad humana sea una oportunidad y una elección, no la única opción para procurar una vida digna.

La concreción de Casa en tierra ajena, como todo proceso de producción de un documental, fue una tarea dinámica y versátil. De acuerdo con la epistemología de las ausencias y de las emergencias, el abordaje de las diversas realidades sociales requiere un proceso de traducción que, como explica Boaventura de Sousa Santos, es un trabajo intelectual, político y emocional, porque «presupone un inconformismo ante una carencia» ${ }^{1}$.

El documental, por las características de su lenguaje audiovisual, hace más accesible la investigación científica social a una diversidad de sectores; lo cual, aunado a una extendida práctica de consumo en colectivo o en simultáneo en una misma sala, incita a la conversación, discusión y construcción colectiva. Explica Jean Breschand que «una de las facultades del documental es la de unir estaciones, confrontar épocas, medir el tiempo que transcurre y ver qué es lo que se transforma»².

A su vez, el documental permite conjugar la triada investigación, docencia y extensión/acción social en un material de uso público que favorece el aprendizaje y la sensibilización social. Así, Casa en tierra ajena es un documental publicado en marzo de 2017, año en que la UNED conmemora su 40 aniversario; con este proyecto la UNED, junto a la UCR y CONARE, pone a disposición de la comunidad internacional un documento de primer orden a nivel educativo, analítico y de sensibilización, en un tema prioritario en el mundo, la migración forzada.

En un documental educativo y de incidencia social, la historia finaliza cuando llega a las audiencias, pues cada persona, desde su historia de vida, su posicionamiento político y la coyuntura, termina por dar significado a la narración. Cada palabra, cada imagen, cada sonido, cada silencio tendrá su propia vida en el ámbito racional y emocional de cada persona. Desde esta postura, Casa en tierra ajena pretende movilizar a la sociedad en procura del derecho a migrar y el derecho a no migrar.

1. Boaventura de Sousa Santos, Una epistemología del SUR. La reinvención del conocimiento y la emancipación social (México: Siglo XXI \& CLACSO, 2009), 143.

2. Jean Breschand, El documental la otra cara del cine (España: Impresiones Paidós Ibérica, 2004), 43. 
Casa en tierra ajena es un documental transmedia sobre la migración forzada de personas centroamericanas rumbo a los Estados Unidos. El documental transmedia es una narrativa intertextual que, de acuerdo con Vicente Gosciola, se caracteriza por ser «una estructura narrativa, o una gran historia, expandida y dividida en fragmentos que son distribuidos en diversas plataformas mediáticas. La adopción de redes sociales, como la blogosfera, y la multiplicación de su contenido a partir de procesos virales y/o interactivos también son factores presentes en la narrativa transmedia» ${ }^{3}$.

En concreto, Casa en tierra ajena contempla:

- Libro: No más muros. Exclusión y migración forzada en Centroamérica, escrito por el Dr. Carlos Sandoval García, especialista en la temática migratoria y funcionario de la Universidad de Costa Rica (UCR).

- Largometraje documental: organizado en tres capítulos y temáticas. El capítulo 1, El derecho a no migrar, explica los factores de expulsión; el capítulo 2, El derecho a tener derechos, expone los peligros del viaje y las políticas de control de las migraciones en los países de tránsito y destino; y el capítulo 3, El derecho a la esperanza, habla sobre la solidaridad y hospitalidad de las Casas para Migrantes.

- Reportajes documentales que ahondan en distintas problemáticas y esfuerzos organizativos a favor de los derechos humanos de las personas migrantes y las comunidades en defensa de sus territorios.

- Entrevistas a profundidad con especialistas en diversas áreas que permiten comprender la coyuntura política de los países del llamado Triángulo Norte (El Salvador, Honduras, Guatemala) y México.

- Animación didáctica: sistematiza de manera didáctica los nudos históricos de la geopolítica de las migraciones de Centroamérica a los Estados Unidos.

- Canal de youtube: Casa en tierra ajena

- Página web: http://casaentierrajena.com

- Facebook: https://www.facebook.com/casaentierrajena/?ref=bookmarks

- Trailers:

- Trailer 1: https://www.youtube.com/watch?v=nhc0v-dS7JQ

- Trailer 2: https://www.youtube.com/watch?v=8u9mH4y354A

- Trailer 3: https://www.youtube.com/watch?v=uMcwgBR6gWI

- Trailer Oficial: https://www.youtube.com/watch?v=FD7ANfLwdHU

3. Vicente Gosciola 2011 citado en Denis Porto, Raquel Longhi y Sandra Ruiz, «Diversos géneros en la narrativa transmediática del documental», Revista Comunicación 1 (2012): 225, http://revistacomunicacion. org/pdf/n10/mesa1/018.Diversos_generos_en_la_narrativa_transmediatica_del_documental_33.pdf 
Pasar de la idea al documental requirió elaborar un proyecto sobre contenidos, metodología y presupuesto que se tituló Producción y difusión de un documental sobre migración en Centroamérica, el cual fue escrito y presentado de manera conjunta por el Programa de Producción de Material Audiovisual (PPMA) de la Universidad Estatal a Distancia (UNED) y el Instituto de Investigaciones Sociales (IIS) de la Universidad de Costa Rica (UCR) a fondos concursables del Sistema del Fondo Especial de la Educación Superior de CONARE.

En reconocimiento al aporte del lenguaje audiovisual a los procesos de recuperación de la memoria como medio de contrainformación y empoderamiento social, la siguiente sistematización pretende facilitar una herramienta metodológica sobre la ruta de producción de este proyecto. Para ello, se contemplan las etapas de diseño de proyecto, preproducción, producción, posproducción, devolución y difusión.

\section{Desarrollo}

El tema migratorio es sumamente amplio y diverso. Por ello, elaborar un documental es una tarea que implica definir la narración, realizar el guion, la preproducción, finiquitar las grabaciones para llegar a la posproducción, así como a la devolución y divulgación.

\section{Definir la narración: Guion}

Definir la narración implica decidir qué se quiere contar y cómo se quiere presentar. Explica Syd Field:

Un guión sigue una línea de acción narrativa determinada, concisa y ajustada, una línea de desarrollo. Un guión siempre se mueve hacia delante, siguiendo una dirección, hacia la resolución. Hay que mantener el rumbo a cada paso del camino; cada escena, cada fragmento tiene que llevarlo a alguna parte, haciéndolo avanzar en términos de desarrollo argumental. ${ }^{4}$

Definir la línea argumental es una tarea central en la cual interviene una diversidad de insumos. Entre ellos están libros, como el caso de No más muros: exclusión y migración forzada del investigador Dr. Carlos Sandoval García; pero también gran cantidad de artículos científicos, periódicos, fotografías, audiovisuales (documentales, reportajes de carácter periodístico), redes sociales de organizaciones que dan cuenta del día a día del tema migratorio y conversaciones previas con las personas en contextos de migración forzada en distintas regiones de Centroamérica y México con el uso de tecnologías como Skype.

4. Syd Field, El Manual del Guionista. Ejercicios e instrucciones para escribir un buen guión paso a paso (Madrid: Plot Edidiones, 1996), 14. 
Es importante aclarar que un libro, un artículo o una investigación no es un guion documental. Un libro es una base teórica y una referencia de gran relevancia que debe nutrirse de múltiples fuentes, las cuales posteriormente conforman el guión.

Para el documental Casa en tierra ajena, se definió que la narración se concentrara en tres grandes bloques: factores de expulsión o ¿Por qué la gente migra? Mecanismos de control de las migraciones y los peligros del viaje; y la hospitalidad sin fronteras.

Una de tres características diferenciadoras con otros documentales fue descartar el relato del viaje y de un narrador omnisciente/locutor para hilar las historias, rasgo presente en documentales como La Bestia (2010) y Quién es Dayanni Crystal (2013), entre otros. Otra propuesta innovadora fue el abordaje de los motivos que fuerzan a las personas a migrar más allá de la violencia o las condiciones económicas, pues el enfoque es desde la perspectiva histórica y del modelo de desarrollo extractivista de la acumulación por desposesión, la cual, como explica David Harvey, se refiere al saqueo de recursos que viven los países desde una lógica de pillaje, sobre todo aquellos ubicados en el "Tercer Mundo". Harvey retoma a Marx en la explicación de la acumulación originaria que contempla:

la mercantilización y privatización de la tierra y la expulsión forzosa de poblaciones campesinas; la conversión de diversas formas de derechos de propiedad -común, colectiva, estatal, etc.- en derechos de propiedad exclusivos; la supresión del derechos a los bienes comunes; la transformación de la fuerza de trabajo en mercancía y la supresión de formas de producción y consumo alternativas; los procesos coloniales, neocoloniales e imperiales de apropiación de activos, incluyendo los recursos naturales; la monetización de los intercambios y la recaudación de impuestos, particularmente de la tierra; el tráfico de esclavos; y la usura, la deuda pública y finalmente, el sistema de crédito $^{5}$.

A los dos elementos diferenciadores anteriormente mencionados se une la perspectiva del derecho a migrar y el derecho a no migrar.

También se optó por un relato documental que no se restringiera a un solo país, sino que se buscó un abordaje regional que priorizara la migración forzada de personas procedentes del Triángulo Norte (Guatemala, Honduras y El Salvador), debido a que este presenta el mayor porcentaje de migración centroamericana y porque sus habitantes se enfrentan a un contexto de país expulsor y país de tránsito con más amenazas y vulnerabilidades.

Entre los factores de expulsión para la migración forzada se abordó el contexto histórico de las guerras en Guatemala (1982 -1996) y El Salvador (1980 - 1992) con el devenir de los Acuerdos de Paz, en medio de corrupción e impunidad, los cuales no lograron llevar a la justicia a los actores de crímenes de lesa humanidad y cuyas heridas siguen vigentes en la población. Otros factores son la violencia de pandillas como la Mara 18 y la Mara Salvatrucha en El Salvador, así como la migración por violencia

5. David Harvey, El nuevo imperialismo (Madrid: AKAL, 2003), 113. 
estructural cuando no se puede acceder a vivienda, salud, educación y hasta alimento para la familia. A estos se suman otros como la migración forzada vinculada al modelo de desarrollo extractivista.

En un país como Guatemala, el Instituto Nacional de Energía y Minas reporta la existencia de 307 licencias mineras vigentes y 559 en trámite para la explotación minera ${ }^{6}$. En cuanto a las plantas hidroeléctricas, hay 31 proyectos en operación, trece en construcción, catorce autorizados que no han iniciado la construcción y seis en trámite, lo cual da un total de 64 proyectos hidroeléctricos ${ }^{7}$.

En Honduras, el desarrollo de megaproyectos turísticos es factor para la migración forzada. El caso concreto de Indura Resort, que inició en el 2003 -es una inversión público-privada de aproximadamente $\$ 122$ millones-, acapara más de tres kilómetros de playa y forma parte del Plan de la Alianza para la Prosperidad en el Triángulo Norte ${ }^{8}$.

El monocultivo extendido de palma africana también es factor de expulsión debido al despojo de tierras campesinas y a la criminalización de la protesta social. Se calcula que en Honduras, entre el 2004 y 2017, la cobertura de palma africana pasó de 69 mil hectáreas a 150 mil hectáreas, además se estima que tres empresas controlan el 61\% de la producción, concretamente una9 .

A nivel de los peligros del viaje se expone el tema de los secuestros, extorsiones, golpizas y masacres colectivas como Cadereyta, Tamaulipas y Tamaulipas II, perpetradas por el crimen organizado. Pero también se habla de una corroída institucionalidad en países como México, donde agentes de migración y policía estatal y federal participan de la violación a los derechos humanos de las personas migrantes.

En cuanto a las políticas de control de las migraciones, se abordan explicaciones sobre la exigencia de la VISA mexicana para los centroamericanos (excepto los costarricenses) como mecanismo de control que en el tránsito de la migración forzada expone a las personas migrantes a los trayectos más peligrosos a nivel de crimen, condiciones climáticas y largos periodos de viaje para evadir controles. De igual forma, México se ha convertido en la gran frontera vertical sur: reportes oficiales indican que entre 2013 y 2014 el número de personas deportadas desde México a Centroamérica pasó de 72692 a 114009 , lo cual representa un incremento de $63,75 \%{ }^{10}$.

6. Instituto Nacional de Energía y Minas, Energía. Estadísticas Mineras. Licencias Vigentes y Solicitudes en Trámite (2017a), http://www.mem.gob.gt/mineria/estadisticas-mineras/ licencias-vigentes-y-solicitudes-en-tramite/

7. Instituto Nacional de Energía y Minas, Dirección General de Energía Departamento de Desarrollo Energético (2017b), http://www.mem.gob.gt/wp-content/uploads/2015/06/1._-Listado-de-HidroeléctricasMayores-a-5-MW.pdf

8. Radio Progreso, «Bahía de Tela. Tercer destierro» (2015), http://radioprogresohn.net/index.php/ comunicaciones/alef/item/2579-bah\%C3\%ADa-de-tela-el-tercer-destierro

9. Nelson Rauda, Ximena Villagrán y Raúl Sánchez, «Honduras no quiere bisque, quiere aceite de palma», Diario El Faro, 25 de abril de 2017, https://elfaro.net/es/201704/centroamerica/20080/Honduras-noquiere-bosque-quiere-aceite-de-palma.htm

10. La Prensa Libre. «Deportación de centroamericanos desde México aumenta 75,8\% en 2015», La Prensa Libre, 15 de abril de 2015, http:/www.prensalibre.com/guatemala/migrantes/ deportacion-de-centroamericanos-desde-mexico-aumenta-758-en-2015 
El tercer gran bloque de contenido viene dado por la hospitalidad de las Casas para Migrantes que se encuentran a lo largo de la ruta migratoria. Se calcula que en México hay 66 casas.

Así, tras un proceso de investigación, conversación y trabajo regional, se logró crear un guión literario, el cual fue la guía para elaborar el plan de grabación y realizar el trabajo de campo.

\section{Preproducción del documental}

La preproducción de un documental implica todo el proceso de planificación que permite llevar las ideas del guión literario a las imágenes.

Para Casa en tierra ajena toda la preproducción se realizó desde Costa Rica. Por ello, la comunicación entablada con comunidades y organizaciones en el proceso de guión fue fundamental para planificar esta etapa. Con el guión literario finalizado, se contactó a productores de campo en cada país, es decir, personas que colaboraron en coordinar logísticamente las grabaciones por países, y quienes, a su vez, debían ser personas con cercanía, compromiso y vinculación al tema migratorio.

Al tratarse de un tema tan delicado, atravesado por el empobrecimiento, las carencias y la represión, era necesario trabajar desde la confianza política y personal en procura de que las personas de las comunidades tuvieran una mayor apertura con el equipo de producción. En México se trabajó con tres productores de campo y con las siguientes organizaciones: Casa del Migrante Mambré en Comitán de Domínguez (Chiapas), Casa del Migrante de Saltillo (Saltillo, Coahuila), Casa del Migrante Emaus, Frontera y Dignidad (Ciudad Acuña, Coahuila), Colegio de la Frontera Sur (ECOSUR) y Comisión Nacional de los Derechos Humanos (CNDH, México).

En Guatemala hubo dos productores de campo y la vinculación fue con la Universidad Rafael Landívar (Unidad de Coordinación del Sistema de Apoyo al Apostolado Social, Vicerrectoría de Investigación y Proyección), la Asociación de Desarrollo del Ixcán (ADESI), Tzk'at: Red de Sanadoras Ancestrales del Feminismo Comunitario desde Iximulew-Guatemala, la Organización de Apoyo a una Sexualidad Integral frente al Sida -OASIS-y Asamblea de Pueblos de Huehuetenango por la Defensa del territorio-ADH-.

Para el trabajo de campo en El Salvador se laboró en diálogo con la Universidad Centroamericana José Simeón Cañas (UCA), la Asociación Comité de Familiares de Migrantes Fallecidos y Desaparecidos de El Salvador (COFAMIDE), el Museo de la Palabra y la Imagen (MUPI) y el Programa Bienvenido a Casa, la Dirección General de Migración y Extranjería, y la Dirección de Atención al Migrante.

Finalmente, en Honduras se logró trabajar con una productora y las siguientes organizaciones: Radio Progreso, Equipo de Reflexión, Investigación y Comunicación (ERICSJ), Organización Fraternal Negra Hondureña (OFRANEH), Observatorio de Derechos Humanos del Aguán y Comité de Familiares de Migrantes de El Progreso (COFAMIPRO).

De forma paralela al contacto y la definición de los productores de campo, quienes apoyaron la labor de confirmación y logística que permitió grabar con las organizaciones 
previamente establecidas en el guión literario, se elaboró un plan de grabación, el cual es una herramienta fundamental pues traza la logística por seguir para grabar las historias.

En primera instancia, se definieron dos grandes giras de grabación, cada una de ellas de quince días. La primera se realizó en setiembre de 2015 a Honduras y El Salvador; la segunda fue en febrero de 2016 y contempló Guatemala y México. Para la optimización del tiempo y el cálculo de las rutas se empleó la herramienta de Google Maps y, por supuesto, la comunicación con los productores de campo y conductores de cada país.

Las decisiones sobre el equipo tecnológico de las grabaciones decantaron en el empleo de cuatro cámaras de alta definición. Esto permitió que un equipo conformado por solamente cuatro personas pudiera realizar en tan corto plazo la grabación de tan variados temas. Las cámaras utilizadas fueron Sony NXDCAM, GoPro, Cannon 5D y Cannon 60D. A ellas se suman micrófono, trípodes, computadores, etc. Posteriormente, en varias secuencias, se empleó una cámara Sony F55. En situaciones específicas donde la seguridad era más compleja, como las estaciones de autobuses y las comunidades rodeadas por pandillas, se prefirió grabar con la GoPro por ser una cámara pequeña. Aunado a ello, las entrevistas se grabaron con dos cámaras de forma simultánea, en distintos valores de plano, lo cual permitió optimizar el tiempo, tener un doble respaldo de la grabación y más posibilidades de corte en el momento del montaje, considerando que el proyecto es claramente un documental testimonial.

El testimonio tiene una aparición histórica y constante en el documental que se aborda principalmente desde la entrevista. Esta es dirigida por la directora o realizadora, con el fin de provocar declaraciones, análisis y reflexión en relación con los temas o situaciones específicas que son de su interés para traer al documental. Como explica Lorena Moriconi, «más que de escuchar, se trata en este caso de hacer hablar» ${ }^{11}$.

En la preproducción también se contempló la vinculación con diversos colegas a nivel internacional para acceder a imágenes de archivo autorizado, principalmente imágenes de carácter histórico de procesos de desalojo, abuso policial y defensa territorial y de derechos humanos de diversas organizaciones, comunidades y países. Algunos de estos archivos en video y fotografía tenían carácter profesional y otros eran grabaciones ciudadanas con teléfonos móviles o cámaras más modestas. Igualmente, a nivel de registro tenían un potencial narrativo, argumentativo y eran prueba fidedigna de diversos acontecimientos.

Todas las imágenes fueron cedidas por los titulares de derecho de forma gratuita para el uso exclusivo del proyecto documental por tener fines educativos, de incidencia social y no comercialización.

Si bien el documental prescinde del relato del viaje como hilo narrativo, una de las decisiones que se tomó fue la de construir una secuencia de seguimiento a migrantes, la cual se grabó en Costa Rica, a modo de recreación, debido a las dificultades y peligros que conlleva entrar con una cámara a esos espacios. Para ello, se trabajó en ocho

11. Lorena Moriconi, «Voces filmadas: cine documental, testimonio y dictadura (Argentina, 1983-2002)», Revista Cine Documental, n. ${ }^{\circ}$, (2012), http://revista.cinedocumental.com.ar/6/teoria.html 
locaciones distintas con dos grupos diferentes de jóvenes de edades muy similares a las de las personas con quienes conversamos a lo largo del documental.

\section{Producción y grabación}

La fase de producción se explica a partir del proceso de grabación. Para ambas giras la dinámica fue muy similar, se trabajó con un equipo conformado por cuatro personas: Carlos Sandoval García, Santiago Martínez, Michele Ferris e Ivannia Villalobos. El diseño de producción del documental intentó dejar la menor cantidad de situaciones al azar y todas las entrevistas o locaciones estaban previamente coordinadas, confirmadas y autorizadas.

Entrar a cada comunidad, organización o casa implicó un proceso de mucho respeto y diálogo con cada uno de los entrevistados. Con la autorización de las personas se iniciaba el proceso de selección del espacio para grabar la entrevista, se armaba el equipo (cámara, sonido) y se procedía a la realización de la entrevista guiada por los contenidos del guión literario (por supuesto, existe una gran versatilidad para agregar nuevas consultas o el modo de plantearlas, con el fin de ayudar a la persona entrevistada en el proceso de comunicar sus vivencias). Todas las entrevistas tuvieron una duración de entre 30 y 50 minutos cada una, aproximadamente.

También se realizaron las imágenes de apoyo o seguimiento de personajes. Siempre se buscaron espacios, retratos y momentos significativos para cada historia de vida; es decir, no solo la imagen por la imagen, sino su semántica para la narración.

A nivel fotográfico y de producción, se decidió trabajar con la luz natural. Esto permitió desarrollar el proceso de grabación con la menor intervención artificial del espacio y la cotidianidad, así como mostrar de una manera más auténtica la realidad en la cual viven las comunidades que están siendo forzadas a migrar, las rutas del tránsito migratorio y las casas para migrantes. A su vez, agilizó los procesos de grabación en cada lugar y facilitó viajar con un equipo más liviano y menos vistoso.

Al finalizar cada día de trabajo, las cámaras debían ser revisadas, limpiadas y sus baterías recargadas. De igual manera, el material grabado debía transferirse de las tarjetas a los discos externos, pues esas mismas tarjetas se ocupaban al día siguiente. Por motivos de seguridad, se realizaba un triple respaldo del material de las tarjetas: disco externo 1, disco externo 2 (espejo) y disco duro de la computadora. Esto implicaba un promedio de dos horas y media diarias de trabajo al final de cada día.

\section{Postproducción del documental}

La postproducción es una fase compleja y creativa. Roy Thompson explica que existen cinco tipos de montaje: por acción, por posición de pantalla, montaje formal, montaje conceptual y montaje combinado. En Casa en tierra ajena se trabajó un montaje

12. Roy Thompson, Manual de montaje (Madrid: Plot Ediciones, 2001), 67. 
combinado priorizando el montaje conceptual o montaje de ideas y el combinado, el cual requiere de «un montador capaz de reconocer el potencial sonoro y visual de cada plano como contribución al montaje combinado» ${ }^{12}$.

La metodología seguida para Casa en tierra ajena se enfocó en el montaje a partir de las 55 entrevistas, considerando que se trata de un documental de tipo testimonial. La mitad de las entrevistas fue transcrita y la otra mitad fue estudiada directamente por la directora en la línea del tiempo del software de edición, quien trabajó el primer borrador de edición.

Todas las entrevistas se escucharon cuidadosamente, ubicando las frases o intervenciones contundentes que contribuyeran a explicar cada bloque temático y al hilo narrativo. La selección de cada intervención es un proceso delicado, pues debe tomarse en cuenta la importancia de la síntesis sin afectar éticamente el relato, procurando así que la yuxtaposición de ideas no altere la expresión, el análisis ni las emociones de los entrevistados. Es por esto que las entrevistas deben escucharse varias veces y se debe dejar las marcas en los puntos clave del relato, dejar descansar el oído y retomar el corte.

Aunado a ello, en el proceso de dar dirección al relato, se recurre a reacomodar el orden de la expresión de los eventos, pues es usual que en un relato oral se den paréntesis argumentativos para contextualizar a nivel histórico. La dirección lo que procura es "ordenar" esas ideas, considerando la claridad del relato final, el tratamiento y el arco narrativo.

Como metodología de montaje, la directora trabajó esquemas argumentativos por cada entrevistado. Esto permitía agregar o desagregar las intervenciones de cada uno de ellos según funcionaran para el montaje final, así como tejer puentes entre cada uno de los temas.

Otro gran momento de la postproducción fue la selección de las imágenes de apoyo. Esta fase es importante para encontrar recursos narrativos que permitan construir significación y emoción sin el uso de las entrevistas para redundar los contenidos (la redundancia es un recurso de la comunicación y la didáctica de relevancia para puntualizar ideas) o para elaborar propuestas más semánticas.

El dinamismo del proceso de montaje documental implica considerar que no existe una propuesta única de estructura, sino que se trata de un continuo trabajo de poner, mover, quitar, adelantar, atrasar, ampliar o acortar las intervenciones en el relato. El primer corte del documental duró aproximadamente tres meses a tiempo completo por parte de la directora, después del cual se obtuvo una propuesta de estructura documental para entrar a la sala de edición con el montajista.

La propuesta que llegó a la sala de edición tenía dos horas (120 minutos) de duración, que finalmente se logró concretar en 80 minutos.

El aporte del trabajo del montajista es fundamental. El montaje es un proceso que combina profesionalismo, perspectiva política, destrezas comunicativas, destrezas didácticas, sensibilidad narrativa y destrezas técnicas que permitan que las audiencias se involucren en el relato de manera fluida y orgánica. 
Uno de los retos de la edición fue, en primera instancia, cuando tuvieron que salir del corte varios entrevistados o contenidos. Tal fue el caso de las experiencias de migración en Guatemala, debido a la persecución que viven las poblaciones de la diversidad sexual, y las experiencias organizativas de los Comités de Familiares de Migrantes Desaparecidos y Fallecidos tanto de Honduras como de El Salvador (COFAMIDE y COFAMIPRO). El segundo reto fue establecer el ritmo de montaje documental con la limitada cantidad de imágenes de apoyo, contexto y/o seguimiento de personajes. Sin embargo, logró construirse a partir de los recursos disponibles un relato equilibrado entre entrevistas y secuencias de "descanso" o más contemplativas que permitieran una mejor expresión comunicativa y artística.

Una vez concretado el corte o narración final del documental, el trabajo continuó en los departamentos de diseño gráfico y animación, colorización, diseño sonoro, musicalización y subtitulado. Estas cinco etapas dieron como resultado el documental con todos sus acabados.

El diseño gráfico en Casa en tierra ajena corresponde a todos los elementos tipográficos que aparecen en el documental tales como logo, súper (nombre que identifica el nombre de las personas y sus países), insertos gráficos (son los datos, porcentajes, fechas históricas o información que identifica lugares o situaciones) y los créditos (son las indicaciones en pantalla de roles de producción, agradecimientos, colaboradores, etc.).

Se partió del principio de que el documental tendría una intervención minimalista a nivel de diseño gráfico y animación. Fue necesario un involucramiento directo del especialista en el área mediante la conversación y al acceso directo a diversas secuencias, primero, y luego al documental completo.

Una vez definida la línea gráfica, esta fue trasladada a las demás producciones de materiales adicionales, página web, redes sociales y diversos productos gráficos; entre ellos, afiches, portada para DVD/BluRay, diseño de impresión sobre disco, menú de discos, postales, etc.

Además, a nivel de diseño y animación 2D se recurrió a esta herramienta comunicativa y didáctica para generar un material adicional sobre los nudos históricos geopolíticos de la migración centroamericana hacia los Estados Unidos.

Los procesos de musicalización, posproducción de sonido y colorización del documental podrían explicarse como un volver a armar el documental, esto porque cada uno aporta nuevo contenido y emotividad a la narración. Un ejemplo que podría explicar este proceso es la construcción de una casa, cuando acabada la obra gris empiezan todos los acabados que llegan a darle personalidad a esa estructura.

A nivel de musicalización se elaboró una guía o guion del trabajo sonoro del documental completo y un mapa musical, donde la intención estuvo marcada por la construcción de atmósferas y sensaciones, por lo cual se priorizaron las tonadas largas, la exclusión de patrones rítmicos y la metáfora de que la música debe abrazar a los personajes del documental y a la audiencia. Se evitaron musicalizaciones en extremo dramáticas, pues los testimonios y las historias son lo suficientemente impactantes y debe cuidarse no caer en el sensacionalismo en relación con un tema tan delicado a nivel humanitario. 
El guión de musicalización estuvo accesible al posproductor de sonido porque contemplaba las indicaciones de que el protagonismo sonoro estaba en la construcción de los ambientes y no en la música y viceversa; de tal manera que un esfuerzo conceptual a nivel sonoro y de musicalización no opacara al otro o redundara al punto de saturar la narración.

La fase de postproducción de sonido es un trabajo extremadamente creativo. En el caso del documental Casa en tierra ajena, el hecho de no contar con un sonidista de campo durante las dos giras de grabación hacía que esta tarea fuese aún más relevante. Así se logró mejorar la calidad de audio de varias entrevistas en las cuales los ambientes o algunos ruidos interrumpían o competían con el audio principal; mejorar la calidad de grabaciones de archivo histórico como la resistencia insurgente de Radio Venceremos en El Salvador; y construir ambientes diegéticos (sonidos que están directamente en la puesta en escena) y no dietéticos (aquellos que tienen un carácter más semántico). El silencio también es un recurso narrativo.

Otra labor que se abordó fue la colorización, proceso fundamental para estandarizar la calidad visual de las cinco cámaras empleadas. Una vez conseguido esto, se entra en un proceso más conceptual y creativo.

Se optó por una propuesta de colorización más fría y desaturada en los primeros dos bloques por tratarse de contenidos ligados a los factores de expulsión y las políticas de control. Ambos narran historias de despojo y violencia dentro de sus comunidades y países, así como en la ruta migratoria. De esta manera, los tonos más fríos y desaturados contribuían semánticamente a reforzar la comunicación con las audiencias. Para el tercer bloque se conceptualizó una corrección de color más cálida y saturada, pues su contenido está cimentado en la solidaridad y la hospitalidad que brindan las Casas para Migrantes. Así, para el paso del segundo bloque al tercero se recurrió a una transición larga de color en el plano que presenta la ciudad de Comitán (Chiapas, México), con el cual se entra al tercer bloque, para dar armonía visual a ese cambio.

El subtitulado del documental se realizó con el objetivo de llegar a un público diverso y favorecer la accesibilidad de los contenidos. En la primera etapa, se cuenta con subtítulos en español e inglés. Esto implicó la transcripción literal de los diálogos y la codificación minuciosa del código de tiempo en español, con base en la cual se realizó la traducción al inglés. Ya con los recursos finales (clip documental, archivos .txt de los subtítulos y diseños de pantallas de DVD) se procedió a programar el DVD y BluRay con subtítulos activables y desactivables, así como a ingestar dichos subtítulos en la versión web.

\section{Conclusión}

El documental sobre migración forzada en Centroamérica Casa en tierra ajena, como producto final y como proceso de trabajo, es el resultado de un diálogo de saberes, del trabajo colaborativo y del compromiso político a escala regional. La determinación de la importancia de crear un audiovisual sobre el derecho a migrar y el derecho a no migrar logró estrechar los lazos que transcienden fronteras del equipo productor en Costa Rica, los productores de campo en cada país, los testimonios de organizaciones y líderes 
comunitarios, así como las imágenes de archivo facilitadas por organizaciones, productoras y documentalistas/fotógrafos independientes.

Casa en tierra ajena es un proyecto que, de cara al 40 aniversario de la Universidad Estatal a Distancia (UNED), muestra las diversas potencialidades que ha logrado construir esta casa de estudios superiores desde su fundación. Entre ellas, la producción de materiales audiovisuales didácticos como una herramienta pedagógica y académica en el modelo de educación a distancia; la capacidad de vinculación internacional de la UNED, tanto a nivel institucional como comunitario; el trabajo interinstitucional e interuniversitario que es modelo para el mundo como sistema de universidades públicas en Costa Rica; el fortalecimiento de los componentes de democratización e internacionalización del quehacer universitario con la producción y difusión de un documental sobre migración forzada en una coyuntura internacional de alta pertinencia y discusión. A su vez, este proyecto, al concretarse en el año del 40 aniversario de la UNED, muestra una universidad que reúne experiencia y modernización sin perder de vista la calidad, la pertinencia y el impacto de su quehacer.

Así, la realización del documental es el resultado del trabajo interuniversitario gestado por la Universidad Estatal a Distancia (UNED), la Universidad de Costa Rica (UCR) y el apoyo financiero del Consejo Nacional de Rectores (CONARE), que de manera conjunta atienden la educación como eje de desarrollo humano, inclusión social y democratización del conocimiento.

Casa en tierra ajena es un documental transmediático que integra investigación, docencia y acción social. Toma como base el libro No más muros: exclusión y migración forzada en Centroamérica del Dr. Carlos Sandoval García y, a su vez, una serie de insumos tanto escritos como audiovisuales. El lenguaje audiovisual, por sus características, permite llevar contenidos, así como también sensibilizar sobre un tema tan importante a un público muy diverso y hacer más accesible la investigación científica social. Debido a su abordaje, se convierte en material didáctico con usos en diversas áreas del conocimiento (historia, derechos humanos, desarrollo, geopolítica, etc.). También es herramienta de acción social por las interacciones sociales que genera su proyección, difusión y diálogo en colectivo.

Por la complejidad de la ruta de producción y, a su vez, por la clara y sencilla forma de exponer los contenidos, Casa en tierra ajena no concluye en el proceso de edición. Este documental llega realmente a concluirse cada vez que se proyecta, cada vez que se genera conversación y discusión que lleva a la acción y transformación social. El objetivo del documental no es permanecer en una mediateca, sino ser un documento de apropiación y resignificación colectiva.

También, por los diversos escenarios de abordaje y posibilidades narrativas, la ruta de producción del documental promueve la realización de nuevas investigaciones y documentales que permitan dar continuidad al tema, comprender las complejidades estructurales de la región y también documentar los espacios de rupturas sociales que nos permitan vislumbrar alternativas para el buen vivir de los pueblos.

Finalmente, Casa en tierra ajena se convierte en un importante antecedente de producción en el marco del 40 aniversario de la Universidad Estatal a Distancia (UNED) 
con el cual se logra una vinculación con otras universidades públicas, organizaciones y canales de difusión educativa y cultural a nivel internacional que publican, proyectan y generan diálogos a partir de una producción audiovisual universitaria comprometida con la rigurosidad académica, la calidad narrativa y el bienestar de las sociedades sin límites de fronteras o nacionalidades.

\section{ABSTRACT \\ Route to the Production House in Foreigner Land: Documentary on forced migration in Central America}

The Distance State University (UNED), in its 40th year since founded, accumulates an experience of documentary production of didactic materials of great quality, in the country as well as the region. This has been recognized with more than 40 national and international awards towards the materials produced specifically by the Material and Audiovisual Productions Program (PPMA).

Each process of audiovisual production has its rhythms and particularities. In this article, we expose the stages and key decisions of production of the documentary about forced migration in Central America "House in foreigner land" a Distance State University (UNED) and University of Costa Rica (UCR) production, with the financial support of the National Council of Deans (CONARE). In the year of UNED's fortieth anniversary, "House in foreigner land" made its debut. This was the first full length film documentary produced by UNED with production and recording that included Central America and Mexico. This film follows the path of UNED's productions, which is commitment and impact, characteristic of its diffusion and global impact. As a learning tool, this article addresses the aspects related to the factors that influenced in the construction of the project and the objectives of the production team in an educative documentary of social impact. Also, moments and key decisions of the pre-production stage, production and post-production stages are described. This leads to a process of rigorous production in the academic and sensitive human dimension.

Key words: migration, documentary production, Central America, hospitality.

\section{RÉSUMÉ}

\section{Chaîne de fabrication de Casa en tierra ajena (Maison en pays étranger) Documentaire sur immigration forcée dans l'Amérique Centrale}

L'Universidad Estatal a Distancia (UNED) - Université de l'État à Distance- après 40 ans d'être fondée a accumulé de l'expérience dans la production de matériel didactique du genre documentaire de grande qualité aussi bien au plan national qu'au plan de la région. Ceci a été reconnu et plus de 40 prix et récompenses nationales et internationales pour la production réalisée, notamment celle du Programa de Production de Material Audiovisual (PPMA) - Programme de Production de Matériel Audiovisual) - le témoignent.

Chaque processus de production audiovisuel a son rythme de travail et particularités. Dans le suivant article sont exposées les étapes et décisions clés dans la chaîne de fabrication du documentaire sur l'immigration forcée dans l'Amérique Centrale Casa en tierra ajena, - Maison en pays étranger- une production de l'Universidad Estatal a Distancia (UNED) et l'Universidad de Costa Rica (Université du Costa Rica) avec le soutien financier du Consejo Naional de Rectores (CONARE) - Conseil National des Présidentes d'Universités publiques. Dans le $40^{\text {ème }}$ anniversaire de l'UNED, le premier long métrage documentaire Casa en tierra ajena a été montré. Ce documentaire, réalisé par l'UNED avec une échelle de fabrication et d'enregistrement qui comprend l'Amérique Centrale et le Mexique, met en évidence l'engagement et l'impact distinctif des productions UNED et continue avec la diffusion et l'impact global. 
Comme outil d'apprentissage, cet article aborde les aspects liés aux facteurs qui influent la construction du projet et les objectifs de l'équipe de production dans un documentaire éducatif et d'incidence sociale. En outre, on décrit les décisions clés dans les étapes de préproduction, production et post-production qui ont conduit à un processus de fabrication rigoureux dans le domaine académique et délicat dans la dimension humaine.

Mots clés: migration, production documentaire, Amérique Centrale, hospitalité.

\section{Bibliografía}

Breschand, Jean. El Documental la otra cara del cine. España: Impresiones Paidós Ibérica, 2004.

De Sousa Santos, Boaventura. Una epistemología del SUR. La Reinvención del Conocimiento y la Emancipación Social. México: Siglo XXI \& CLACSO, 2009.

Field, Syd. El Manual del Guiónista. Ejercicios e instrucciones para escribir un buen guión paso a paso. Madrid: Plot Ediciones, 1996.

Harvey, David. El nuevo imperialismo. Madrid: AKAL, 2003.

Instituto Nacional de Energía y Minas. Energía. Estadísticas Mineras. Licencias Vigentes y Solicitudes en Trámite. Guatemala, 2017a. http://www.mem.gob.gt/mineria/estadisticas-mineras/ licencias-vigentes-y-solicitudes-en-tramite/

Instituto Nacional de Energía y Minas. Dirección General de Energía Departamento de Desarrollo Energético. 2017b. http://www.mem.gob.gt/wp-content/uploads/2015/06/1._-Listado-de-Hidroeléctricas-Mayores-a5-MW.pdf

La Prensa Libre. «Deportación de centroamericanos desde México aumenta 75,8\% en 2015», La Prensa Libre, 15 de abril de 2015. http://www.prensalibre.com/guatemala/migrantes/ deportacion-de-centroamericanos-desde-mexico-aumenta-758-en-2015

Moriconi, Lorena. «Voces filmadas: cine documental, testimonio y dictadura (Argentina, 1983-2002)». Revista Cine Documental, n. ${ }^{\circ} 6,(2012)$. http://revista.cinedocumental.com.ar/6/teoria.html

Porto, Denis, Longhi, Raquel y Ruíz, Sandra. «Diversos géneros en la narrativa transmediática del documental». Revista Comunicación 1, (2012): 224-235. http://revistacomunicacion.org/pdf/n10/mesa1/018.Diversos_generos_en_la_narrativa_transmediatica_del_documental_33.pdf

Radio Progreso. «Bahía de Tela: Tercer Destierro». Honduras, 2015. http://radioprogresohn.net/index.php/ comunicaciones/alef/item/2579-bah\%C3\%ADa-de-tela-el-tercer-destierro

Rauda Nelson, Villagrán Ximena y Raquel Sánchez. «Honduras no quiere bosque, quiere aceite de palma». Diario El Faro, 25 de abril de 2017. https:/elfaro.net/es/201704/centroamerica/20080/Honduras-no-quiere-bosque-quiere-aceite-de-palma.htm

Thompson, Roy. Manual de Montaje. Madrid: Plot Ediciones, 2001. 
